\title{
Primary oral health care: a missing link in public health in Pakistan
}

S.Basharat ${ }^{7}$, B.T. Shaikh'

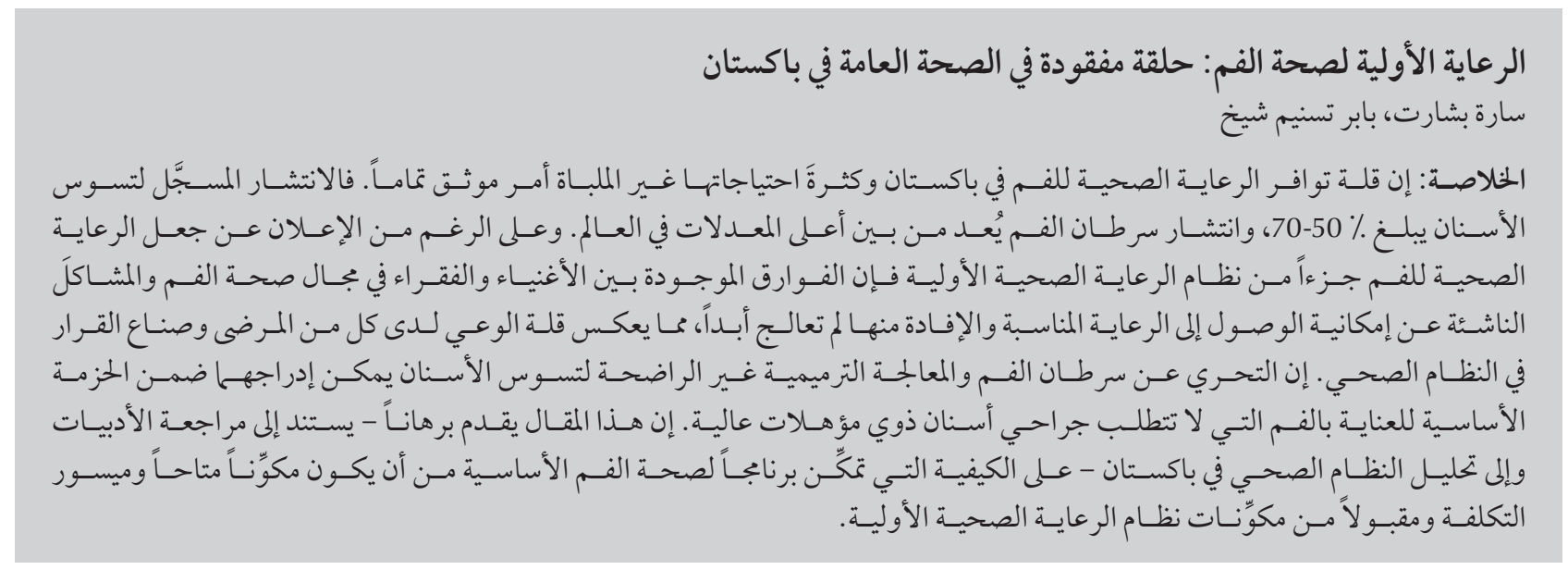

ABSTRACT In Pakistan, the limited availability of oral health care and the high level of unmet oral health care needs are well documented. The recorded prevalence of dental caries is 50-70\% and that of oral cancer is among the highest in the world. Although oral health care has been declared to be part of the primary health care system, oral health disparities between rich and poor, and emerging problems of access to and use of appropriate care have never been addressed, reflecting a lack of awareness among both patients and health system decisionmakers. Oral cancer screening and atraumatic restorative treatment for tooth decay could be included in a basic package of oral care that does not require qualified dental surgeons. This article develops an argument, based on literature review and an analysis of the health system in Pakistan, for how a basic oral health programme could be an accessible, affordable and acceptable component of the primary health care system.

\section{Soins de santé bucco-dentaire primaires : le chaînon manquant de la santé publique au Pakistan}

RÉSUMÉ Au Pakistan, la disponibilité limitée des soins de santé bucco-dentaire et le niveau élevé des besoins non satisfaits dans ce domaine sont bien documentés. La prévalence enregistrée pour les caries dentaires est de 50 à $70 \%$ et celle du cancer de la cavité buccale compte parmi les plus élevées au monde. Bien que les soins de santé bucco-dentaire aient été déclarés comme faisant partie du système de soins de santé primaires, les disparités en matière de santé bucco-dentaire entre riches et pauvres, et les nouveaux problèmes d'accès et de recours aux soins appropriés n'ont jamais été traités, ce qui démontre un manque de prise de conscience des patients et des décideurs du domaine des systèmes de santé. Le dépistage du cancer de la cavité buccale et le traitement restaurateur atraumatique pour les caries dentaires pourraient être inclus à un ensemble de base de soins bucco-dentaires ne requérant pas de chirurgien dentaire qualifié. L'article développe un argument, reposant sur une analyse documentaire et sur l'analyse du système de santé du Pakistan, qui présente la façon dont un programme de santé bucco-dentaire de base pourrait constituer une composante accessible, abordable et acceptable du système de soins de santé primaires. 


\section{Introduction}

Oral health is a state of freedom from chronic mouth and facial pain, oral and throat cancer, oral sores, birth defects such as cleft lip and cleft palate, periodontal (gum) disease, tooth decay and tooth loss, and other diseases and disorders that affect the oral cavity. Risk factors for oral diseases include unhealthy diet, tobacco use, harmful alcohol use, and poor oral hygiene (1). Like other noncommunicable diseases, the global burden of oral diseases has greatly increased in recent years (2), which is of serious concern for both developed and developing countries, as these disorders are the fourth most expensive to treat and monitor (3). The situation is exacerbated by the fact that, in most developing countries, basic oral health care is often not as well designed as other essential components of the primary health care system. This paper argues for the development of a basic package of oral health care at primary health care level in Pakistan, based on evidence about oral health disorders, including tooth decay and oral cancers.

Globally, tooth decay is the most common chronic disease (4). In Pakistan, very little up-to-date information is available on the prevalence of dental caries (which are largely preventable) and other oral health problems. However, research in two large cosmopolitan areas of Pakistan, Karachi and Lahore, found a $50-70 \%$ prevalence of tooth decay in the study population (5-7). Furthermore, according to $\mathrm{WHO}$, cancer of the oropharynx is the sixth most common cancer worldwide; in Pakistan it is the second most common cancer in women and the third most common in men (8). This is of serious concern because no formal programme or basic package of oral care to prevent this cancer exists in the primary health care system (9). The integration of oral health into primary health care has given rise to the idea of "essential oral health" (10).
Affordability and access to oral health care are major problems, which are more pronounced in rural than urban areas (11). The more delayed the diagnosis of cancer, the worse the prognosis, the lower the chances of survival and the greater the cost. The treatment of tooth decay is also more successful with early detection and a conservative approach to cavity restoration (12). Effective public health interventions are therefore needed to improve awareness, knowledge, acceptability, and above all access to oral health care at a cost that is affordable to the general public (13). This is a situation faced by most developing and even some developed countries.

\section{Methods}

An online literature search was conducted on PubMed. This database was chosen because it includes only reputable, peer-reviewed journals. We accessed the most relevant papers from Pakistan and other developing countries (Bangladesh, India, United Republic of Tanzania, Zimbabwe and Latin American countries) on orodental care, public health, and primary health care using the $\mathrm{MeSH}$ terms primary health care, oral hygiene, dental atraumatic restorative treatment, and health system. The full texts of articles were retrieved from Medline/PubMed. Publications of the World Health Organization were also used as basic references.

\section{Findings}

Oral health care has been neglected at primary health care level in most of the developing countries included in our review, and even in some developed countries, such as the United States of America. Although oral health care is part of primary health care in Bangladesh, India, Indonesia, the Islamic Republic of Iran and Nepal $(14,15)$, oral health disparities between rich and poor have not been reduced, and there is inadequate coverage of the population by oral health care services. There are several similarities between Pakistan and India: for example, oral cancer is the most prevalent form of cancer among men in the country $(8,9)$; and dental caries in both India and Pakistan are said to be prevalent among $60-65 \%$ of the population $(5,7,14)$. Pakistan faces an acute shortage of health workers, including dentists; this, combined with rapid population growth, is bound to lead to a need for higher numbers of dental surgeons and auxiliary staff (16). In 1999, India launched a national oral health care programme to address the burden of oral health problems, with a strong focus on prevention, through raising awareness in the community (17). In Pakistan, information about the burden of oral diseases is scarce; however, the issue of limited availability of care and unmet oral health needs is well documented (18). Curative dental services are available at primary health care level in Pakistan in only a few places (19), and cannot deal with the burden of oral cancer and tooth decay. There is thus a need to introduce oral health promotion, screening, restorative treatment, and referral services into existing primary care facilities.

\section{Oral cancers}

A timely diagnosis of oral cancer could mean the difference between life and death. The diagnostic delay comprises a "patient delay" - the time between the patient first noticing a symptom and the first consultation with a health professional - and a "professional delay" - the time between the first consultation and a definitive diagnosis. According to a study conducted in Pakistan, nearly $75 \%$ of oral cancer patients first present when the cancer is at T3 or T4 level (20). Still, merely informing the community about suspicious oral lesions will probably not be sufficient to significantly reduce patient delay. The availability of an appropriate health care provider at a facility that is both accessible and affordable could be greatly beneficial in ensuring 
timely diagnosis and referral (21). Dental auxiliaries have been successfully trained in India to carry out oral cancer screening and dental health promotion (21). Qualified dentists are not required to identify suspicious and potentially malignant lesions. Oral cancer screening could be made available and accessible to high-risk groups in Pakistan, through the introduction of a cadre of dental auxiliaries at primary level.

\section{Tooth decay}

Atraumatic restorative treatment (ART) is a minimally invasive procedure used to prevent and treat dental caries and is specifically designed for use in developing countries. It requires no special electrically driven instruments or professional set-up. Furthermore, the procedure is simple enough to be performed by dental auxiliaries using hand excavation instruments (22). ART was developed to preserve infected teeth, particularly in communities with limited financial resources, little or no provision of piped water or electricity, and limited access to and availability of oral health care (23). It is expected to be practical and useful in Pakistan.

\section{Discussion}

There is an obvious lack of availability of and accessibility to oral and dental health care in Pakistan. Training of community volunteers or informal dental health care providers in dental health promotion and information-sharing with vulnerable communities, and deployment of dental auxiliaries for screening of patients, detection and referral of suspicious oral lesions and provision of basic oral health care could be an efficient and effective way of reducing the burden of oral diseases in Pakistan. The dentistto-population ratio in Pakistan is low (1:10 850) compared with the WHOrecommended level of 1:7500 (1).

In some developed countries with a shortage of human resources in oral health, local health workers are being trained as dental therapists to meet the needs of underprivileged and underserved populations (24). Dental hygienists are also being trained to work as primary oral health care providers (10). Training these auxiliary staff to detect and refer suspicious oral lesions would bring considerable added advantage with little or no added cost in terms of time or financial resources. Such an intervention could have a positive impact on the oral health and quality of life of communities where there are no dentists, hence helping to reduce the disparities in health care provision and oral health status.

Simultaneously, it would be important to introduce a training programme for primary health care workers on primary oral care in Pakistan, and to determine the impact and effectiveness of such a programme in improving awareness about caries prevention and modification of risky behaviour for oral cancer prevention, and in improving access to and affordability of oral health care services in rural areas of Pakistan. It would also be worthwhile to provide refresher training to physicians, to sensitize them about the importance of oral health for general health. In outreach services, lady health workers could be trained to help women understand the need for a clean and healthy mouth.

\section{Conclusion}

ART is a tried and tested technique, and oral cancer screening can be effectively carried out by dental auxiliaries as part of the primary health care system. Because of the significant burden of oral diseases in Pakistan, it is becoming critical to design a model of community-based, selfsustaining, locally supported, effective and basic oral health care in the country.

\section{Funding: None.}

Competing interests: None declared.

\section{References}

1. Oral health. Fact sheet no. 318. Geneva: World Health Organization; 2012 (http://www.who.int/mediacentre/factsheets/ fs318/en/, accessed 5 May 2016).

2. Petersen PE. The World Oral Health Report 2003: Continuous improvement of oral health in the 21st century-the approach of the WHO Global Oral Health Programme. Community Dent Oral Epidemiol. 2003;31 Suppl 1:3-23.

3. Petersen PE. World Health Organization's global policy for improvement of oral health - World Health Assembly 2007. Int Dent J. 2008;58:115-21.

4. Marcenes W, Kassebaum NJ, Bernabe E, Flaxman A, Naghavi M, Lopez A, et al. Global burden of oral conditions in 19902010: a systematic analysis. J Dent Res. 2013;92(7):592-7.

5. Ali S, Bhatti MUD, Syed A, Chaudhry AUH, Iqbal Z. Prevalence of dental caries among 5-14 years old poor locality school children of Lahore. Pak Oral Dent J. 2012;32(2):279-82.
6. Leghari MA, Tanwir F, Ali H. Dental caries prevalence and risk factors among school children age 12-15 years in Malir, Karachi. Pak Oral Dent J. 2012;32(3):484-8.

7. Dawani N, Nisar N, Khan N, Syed S, Tanweer N. Prevalence and factors related to dental caries among pre-school children of Saddar town, Karachi, Pakistan: a cross-sectional study. BMC Oral Health. 2012;12:59.

8. Zahid T, Hussain SI, Siddiqui AH, Junaid ST, Ahmed Z, Noorani MM. Health seeking behavior of oral cancer patients of low socioeconomic status: a cross sectional study in a tertiary care hospital of Karachi. J Dow Univ Health Sci. 2014;8(2):72-9.

9. Cancer country profiles 2014. Geneva: World Health Organization; 2014 (http://www.who.int/cancer/country-profiles/ en/, accessed 5 July 2015). 
10. Monajem S. Integration of oral health into primary health care: the role of dental hygienists and the WHO stewardship. Int J Dent Hyg. 2006;4(1):47-51.

11. Wilson K, Wilson I, Holmes R. Oral urgent treatment (OUT) - a volunteer led training programme in North West Tanzania. $\mathrm{Br}$ Dent J. 2012;212(9):443-8.

12. Brostek A, Walsh L. Minimal intervention dentistry in general practice. Oral Health Dent Manag. 2014;13(2):285-94.

13. Larson TD. Prevention of dental disease versus surgical treatment. Northwest Dent. 2014;93(2):35-8.

14. Gambhir R, Brar P, Singh G, Sofat A, Kakar H. Utilization of dental care: an Indian outlook. J Nat Sci Biol Med. 2013;4(2):292-7.

15. van Palenstein Helderman W, Mikx F, Begum A, Adyatmaka A, Bajracharya M, Kikwilu E, et al. Integrating oral health into primary health care - experiences in Bangladesh, Indonesia, Nepal and Tanzania. Int Dent J. 1999;49(4):240-8.

16. Abdullah A, Mukhtar F, Wazir S, Gilani I, Gorar Z, Shaikh BT. The health workforce crisis in Pakistan: a critical review and the way forward. World Health Popul. 2014;15(3):4-12.

17. Parkash H. National Oral Health Care Program. Indian Pediatr. 2002;39:1001-5.

18. Shah M, Darby M, Bauman D. Improving oral health in Pakistan using dental hygienists. Int J Dent Hyg. 2011;9(1):43-52.

19. Punjab Devolved Social Services Programme. Minimum service delivery standards for primary and secondary health care in Punjab. Lahore: 2010 (http://www.pdssp.gop.pk/down-
loads/documents/MSDS\%20_Health_\%20Final.pdf, accessed 12 June 2015).

20. Shah I, Sefvan O, Luqman U, Ibrahim W, Mehmood S, Alamgir W. Clinical stage of oral cancer patients at the time of initial diagnosis. J Ayub Med Coll. 2010;22(3):61-3.

21. Mathew B, Sankaranarayanan R, Sunilkumar K, Kuruvila B, Pisani P, Nair M. Reproducibility and validity of oral visual inspection by trained health workers in the detection of oral precancer and cancer. Br J Cancer. 1997;76:390-4.

22. Frencken JE, Pilot $\mathrm{T}$, Songpaisan $\mathrm{Y}$, Phantumvanit P. Atraumatic restorative treatment (ART): rationale, technique, and development. J Public Health Dent. 1996;56(3 Spec No):135-40; discussion 61-3.

23. Estupinan-Day S, Tellez M, Kaur S, Milner T, Solari A. Managing dental caries with atraumatic restorative treatment in children: successful experience in three Latin American countries. Rev Panam Salud Publica. 2013;33(4):237-43.

24. Friedman JW, Mathu-Muju KR. Dental therapists: improving access to oral health care for underserved children. Am J Public Health. 2014;104(6):1005-9. 